\title{
COMPARATIVE EVALUATION OF MICROTENSILE BOND STRENGTHS OF POSTERIOR COMPOSITE WITH DIFFERENT LINERS- AN IN VITRO STUDY
}

\author{
Nokku Praveena ${ }^{1}$, Mandava Jyothi ${ }^{2}$ \\ ${ }^{1}$ Assistant Professor, Department of Conservative Dentistry and Endodontics, Apollo Institute of Medical Sciences \& Research, \\ Hyderabad. \\ ${ }^{2} H O D$, Department of Conservative Dentistry and Endodontics, Gitam Dental College and Hospital, Visakhapatnam.
}

ABSTRACT

\section{BACKGROUND}

Aim- The objective of this study is to evaluate the bond strengths of two different liners under the posterior composite restoration.

\section{MATERIALS AND METHODS}

Forty-five freshly extracted human mandibular molars were divided into three groups, ( $\mathrm{n}=15$ each) of 15 specimens each. Standardised MOD cavities were prepared, etching and bonding procedure was performed in all the teeth. In Group A, the flowable liner Z-350 was placed and in Group B, the resin modified glass ionomer liner, Vitrebond was placed and cured. The final restoration was done with Z-250 hybrid composite in incremental pattern. In Group C, composite restoration was placed without any liner. Then the tooth samples were sectioned with a hard tissue microtome into slices of about $1 \mathrm{~mm}^{2}$ and were subjected to microtensile bond strength testing in a universal testing machine, at a cross head speed of $0.5 \mathrm{~mm} / \mathrm{min}$. The values were analysed with one-way ANOVA and Newman-Keuls Post-Hoc test.

\section{RESULTS}

The results indicated statistically significant higher mean bond strength for Flowable Liner Group and Control Group when compared to the resin modified glass ionomer Liner Group.

\section{CONCLUSION}

It can be concluded that in the clinical setting, Z-350 flowable liner provides better bond strengths when compared to the RMGIC liner.

\section{KEYWORDS}

Microtensile Bond Strengths, Flowable Liner, Resin Modified Glass Ionomer Liner, Hard Tissue Microtome, Universal Testing Machine.

HOW TO CITE THIS ARTICLE: Praveena N, Jyothi M. Comparative evaluation of microtensile bond strengths of posterior composite with different liners- an in vitro study. J. Evolution Med. Dent. Sci. 2017;6(38):3073-3077, DOI: $10.14260 /$ Jemds/2017/663

\section{BACKGROUND}

Adhesive bonding of resin composites to dentinal surfaces is far more complex and less reliable. Much debated concern has been focused on polymerization shrinkage related to resin based restorations, that contract $2 \%-4 \%$ by volume during setting. This contraction places the interface between the restoration and the tooth under stress and may result in tooth-composite interfacial debonding, cuspal deflection and enamel cracking which are implicated as the primary reasons for failure of resin bonded restorations.

One of the methods designed to reduce shrinkage stress is use of low-elastic modulus liners like glass ionomer cements, resin-modified glass ionomer cements and flowable composites under the composite. These liners act as a buffer layer that relieves some contraction stresses. Liners are suggested in class II cavities to increase curing rate and the percentage of resin polymerization. ${ }^{1}$

Financial or Other, Competing Interest: None.

Submission 30-03-2017, Peer Review 29-04-2017,

Acceptance 05-05-2017, Published 11-05-2017.

Corresponding Author:

Dr. Nokku Praveena,

Anuhar Colours, Flat No. 506,

D-Block, Plot NO. 66, Survey No. II,

Puppalguda, Manikonda-500089.

E-mail: praveenamds@gmail.com

DOI: $10.14260 /$ jemds $/ 2017 / 663$

Though the literature indicates good but inconsistent results with the use of flowable composite liners and RMGIC liners under the composite restorations, very few studies have presented the comparative analysis of the bond strengths of flowable composite liners with the RMGIC liners. Hence, this study evaluated the microtensile bond strengths of class II composite restorations obtained with flowable and RMGIC liners comparing them to the restorations without any liner.

\section{MATERIALS AND METHODS \\ Specimen Preparation}

Forty-five freshly extracted, periodontally involved, caries free human first mandibular first molar teeth were collected and immersed in $5 \% \mathrm{NaOCl}$ for two hours to attain surface disinfection and dissolution of the superficial soft tissue. Before the start of the cavity preparation, the occlusal enamel was removed up to Dentinoenamel Junction (DEJ) under the running water with the diamond saw to expose a flat superficial dentin. Standardised class II mesio-occluso-distal cavities were prepared with high speed hand piece using a 245 tungsten carbide bur under proper air and water coolant. The buccolingual width of the preparation was kept $3 \mathrm{~mm}$ and the axial wall was prepared to a depth of $1.5 \mathrm{~mm}$ keeping the axial wall parallel to the external contour of the tooth. The gingival seat was placed $1 \mathrm{~mm}$ apical to cementoenamel 
junction (CEJ). The cavity measurements were verified with digital vernier calipers to an accuracy of $\pm 0.01 \mathrm{~mm}$.

Each specimen was mounted in an acrylic block with the adjacent teeth for the placement of matrix, which allowed building the proximal wall. All the prepared MOD cavities were dried with oil free compressed air and acid etched with $37 \%$ phosphoric acid for 15 seconds, rinsed thoroughly with water for 15 seconds. Excess moisture was removed by the tissue paper or damp cotton pellets. The teeth were then randomly divided into three groups each group having 15 specimens, based on the liner that was placed under the composite restoration.

In Group A samples after the acid etching procedure, the bonding agent Adper single bond 2 was applied to the cavity walls with a microbrush and the excess solvent was air dried and light cured for 10 seconds. After placing a sectional matrix with a separating ring a flowable liner Z-350 was placed in a thickness of $0.5 \mathrm{~mm}$ on the axial wall, pulpal floor and gingival seat that was cured for 40 seconds. Then the rest of the cavity was filled with a hybrid composite, Filtek Z-250 (3M-ESPE, Germany) with a horizontal layering technique. Following the restorative procedure, matrix was removed. The composite restoration was finished and polished.

Group B after the acid etching, a thin consistency of Vitrebond (3M ESPE), a resin modified glass ionomer liner was placed on the axial, pulpal floors and gingival seat of the prepared cavities and was cured for 40 seconds. Then the bonding agent was applied and was cured for 10 seconds, following which the same restorative procedure was carried out as described in Group A.

In Group C, the Control Group, no liner was placed and the cavity was restored with Z-250 resin composite after the acid etching and the bonding procedure. The restored teeth were stored in water at $37^{\circ} \mathrm{C}$ for 1 week and were subjected to the thermocycling for 500 cycles at temperatures of $5^{\circ} \mathrm{C}$ to $55^{\circ} \mathrm{C}$ with a dwell time of 20 seconds.

\section{Bond Strength Evaluation}

All the crown samples embedded in acrylic bocks are sectioned with a hard tissue microtome (Leica SP-1600) under copious water lubrication. Sectioning was done in buccolingual direction to attain three slices of $1 \mathrm{~mm}$ thick each from each tooth. The thickness of each tooth slice was measured and verified up to $1 \mathrm{~mm} \pm 0.01 \mathrm{~mm}$ by means of digital caliper. After the sectioning procedure, a total of the 130 tooth samples were obtained and 5 slices were fractured during sectioning.

The microtensile bond strength testing of the tooth samples was carried out after trimming the samples to hour glass shape. Aluminium molds were used as fixtures for the placement of the sectioned tooth samples in the instron testing machine. (AG-15 Shimadzu Inc. USA). The tooth specimens were then stressed at tension with a cross head speed of $0.5 \mathrm{~mm} / \mathrm{min}$ until failure.

Bond failure load was noted when a sharp decline was observed on the graph. This tensile force at failure was recorded as a voltage from a $100 \mathrm{~N}$ load cell using a Pentium computer with an enhanced multifunction I/0 board and is converted to a tensile stress. Thus, microtensile bond strength in Mega Pascals (MPA) for each specimen was calculated using the following formula.

$\mathrm{s}=\mathrm{L} / \mathrm{A}$,
Where ' $\mathrm{s}$ ' is the bond strength in megapascals (Mpa)

$\mathrm{L}=$ test load $(\mathrm{N})$,

$A=$ adhesive area $\left(\mathrm{mm}^{2}\right)$ measured using a digital caliper prior to the tests.

The data was transferred to Microsoft Excel Software and statistical analysis for group wise comparison of bond strengths was done by analysis of variance test (Table 1).

Pair wise significant difference among the three groups, for MTBS was done by Newman-Keuls multiple post-hoc procedure (Table 2).

\section{The Newman-Keuls Method-}

All sample means are rank-ordered in ascending or descending order for this analysis. A comparison is then made between the largest and smallest sample means within the largest range. A significant difference between the largest and smallest means was taken as rejection of the null hypothesis for that specific range of means. Then step-wise comparison of sample means was done until a final comparison is made with the smallest range of just two means. The null hypotheses within that range was retained when there was no significant difference between the two sample means. Formula for the Newman-Keuls was as below.

$$
q=\frac{\bar{X}_{A}-\bar{X}_{B}}{\sqrt{\frac{M S E}{n}}}
$$

Where ' $q$ ' represents the Studentized range value, XA and $\mathrm{XB}$ are the largest and smallest sample means within a range, MSE is the error variance taken from the ANOVA table and ' $n$ ' is the sample size.

\section{SEM Observation of Fractured Surfaces}

After the bond strength test, fractured specimens from each group were observed under the Scanning Electron Microscope (SEM) to evaluate the type of bond failure. The specimens were washed under tap water and were desiccated with $90 \%$ alcohol, stored overnight at room temperature and they were mounted on aluminium stubs. They were sputter coated with $300 \AA$ to $500 \AA$ of gold palladium at 15 ma for 2 minutes and were examined under Scanning Electron Microscopy (Hitachi, Model no-53400, Tokyo, Japan) at $20 \mathrm{Kv}$ at a working distance of $10 \mathrm{~mm}$. Photomicrographs were taken at $200 \mathrm{X}$ magnification and the failure modes were observed.

\section{RESULTS}

In order to standardise the sample size, 40 samples were taken for each group for bond strength evaluation. The results showed that the Microtensile Bond Strength (MTBS) values obtained in Group A was significantly higher with a mean of 34.753 Mpa and a standard deviation of about 4.1194 when compared to Group B that has shown the mean bond strength of 28.3137 Mpa with a standard deviation of 3.2230. The mean bond strength of Group C was 33.4099 Mpa and the standard deviation was 3.7384 (Table 1).

As it is significant to know the pair wise significant difference among the three groups, for MTBS the NewmanKeuls multiple post-hoc procedure was applied and the results were presented in Table 2 . 
There was no statistical difference between Group A and Control Group, as the P value for the Control Group is greater than $0.05(\mathrm{P}=0.1082)$. There was statistically significant difference between Group B and Control Group, which is in favour of Control Group, as the $\mathrm{P}$ value obtained in the Group $\mathrm{B}$ was less than $0.05(\mathrm{P}=0.0001)$.

SEM images of the respective groups showed that the mode of failure in the debonded specimens in Flowable Liner Group and Control Group is adhesive type. Since the bond formed by the RMGIC liner and the composite restoration is greater than the chemical bonding within the RMGIC liner, cohesive failure occurred within the liner itself resulting in the fracture of the restoration (Figure 1 and 2).

\section{SEM Results}

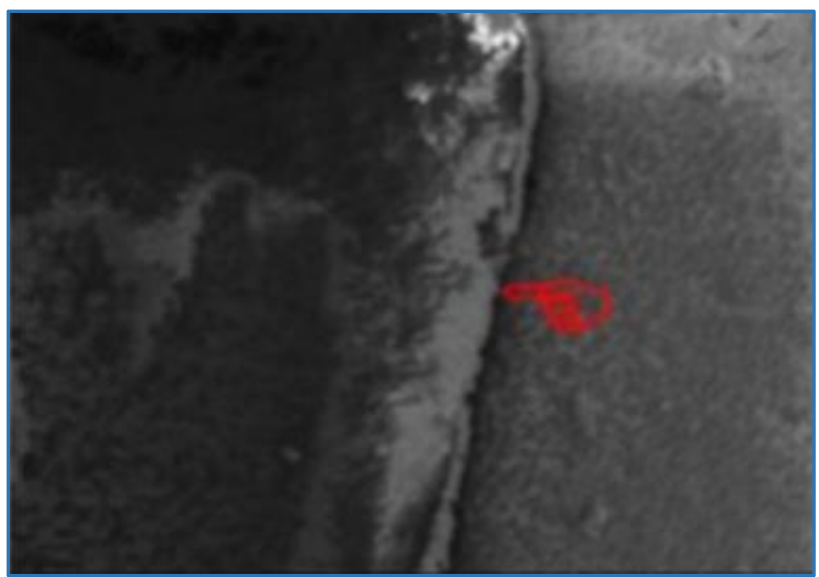

Figure 1. SEM Image of a Debonded Specimen in Group A showing the Adhesive Failure within the Flowable Liner and the Dentin

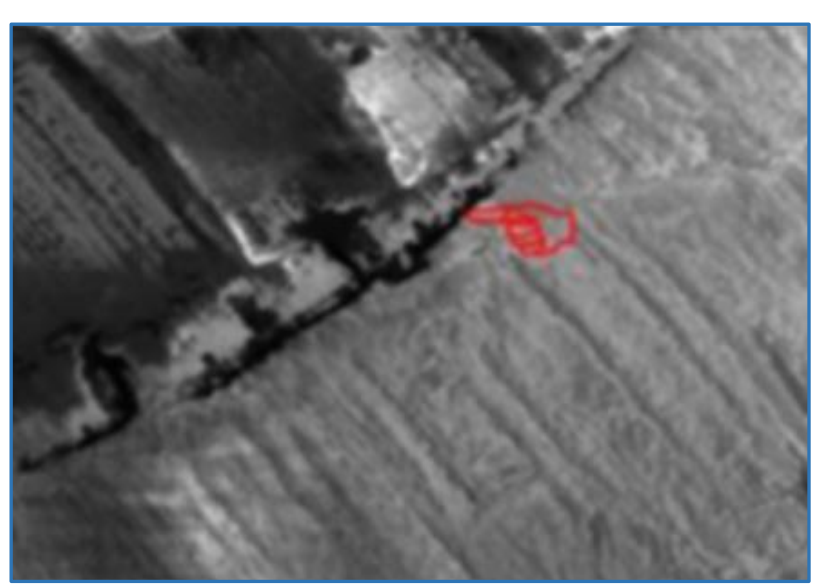

Figure 2. SEM Image of a Debonded Specimen in Group B showing the Cohesive Failure within the Glass Ionomer Itself

\begin{tabular}{|c|c|c|c|c|c|}
\hline Group & N & Means & Std. Dev & $\begin{array}{c}\text { Std. } \\
\text { Error }\end{array}$ & $\begin{array}{c}\text { Coefficient } \\
\text { of Variation }\end{array}$ \\
\hline Group A & 40 & 34.7537 & 4.1194 & 0.6513 & 11.8533 \\
\hline Group B & 40 & 28.3137 & 3.2230 & 0.5096 & 11.3830 \\
\hline $\begin{array}{c}\text { Control } \\
\text { Group }\end{array}$ & 40 & 33.4099 & 3.7384 & 0.5911 & 11.1895 \\
\hline $\begin{array}{c}\text { Table 1. Group Statistics- Mean, Standard Deviation, } \\
\text { Standard Error, Coefficient of Variation of Microtensile } \\
\text { Bond Strength Values according to Three Groups }\end{array}$ \\
\hline
\end{tabular}

\begin{tabular}{|c|c|c|c|}
\hline Groups & Group A & Group B & Control Group \\
\hline Means & 34.75400 & 28.31400 & 33.41000 \\
\hline Group A & - & & \\
\hline Group B & $\mathrm{P}=0.0001^{*}$ & - & \\
\hline Control Group & $\mathrm{P}=0.1082$ & $\mathrm{P}=0.0001^{*}$ & - \\
\hline
\end{tabular}

Table 2. Pair Wise Comparison of Three Groups with Respect to Microtensile Bond Strength by

Newman-Keuls Multiple Post-Hoc Procedures

${ }^{*} \mathrm{p}<0.05$

\section{DISCUSSION}

A successful resin composite restoration depends on the adhesive resin forming a strong and durable bond between the resin composite and the dentin. High percentage of the organic matter and the presence of exosmotic liquid in the dentinal tubules are the important factors that contributes to the difficulty in obtaining a good bond strength to dentin. ${ }^{2}$

The major problem with the class II restoration is the presence of high configuration factor, which leads to creation of contraction forces that may disrupt the bond to cavity walls causing marginal failure and micro leakage. The weakest link of class II composite resin restoration is at the gingival margin of the proximal box. ${ }^{3}$ In class II restoration, as the depth of cure is also decreased, especially at the gingival seat area the polymerization shrinkage is increased creating gap at the resin tooth interface. Hence, in this study class II MOD preparations were considered as an experimental model to simulate the problems that are encountered in invivo situation and the gingival seat of the class II MOD cavities were placed $1 \mathrm{~mm}$ apical to the CEJ.

Filtek $^{\mathrm{TM}}$ Z-250 was used as a composite restorative material, which is a blend between BisEMA and BisGMA and has a higher molecular weight that is said to reduce the polymerization shrinkage, minimises aging effect and increases fracture toughness. Filtek ${ }^{\mathrm{TM}} \mathrm{Z}-350$ was used as a flowable liner that contains nanosilica particles, which are claimed to provide more tensile bond strength to the restorative material. The rationale of selection of flowable composite under the restorative resin is because of the good consistent results in the previous published literature by Bayne SC, Thompson JY, Swift EJ 1998,4 Unterbrink GL, Liebenberg H 1999, ${ }^{5}$ Labella R, Lambrechets P, Vanmeerbeck ${ }^{6}$ 1999, Malmstrom H, Schlueter M, Roach T, Moss M E 2002.7 RMGIC liner as the stress absorbing material was selected to reduce micro leakage based on the reports obtained by Kemp-Scholte CM, Davidson CL 1990,8 Feilzer AJ, De Gee AJ 2000,9 Hagge MS, Linder Muth JS 2001,10 F AndersonWenckert IE, Van Dijkenjw and Horstedt P 2002.11

The microtensile bond strength values of class II cavities obtained with low viscosity flowable liners are significantly high when compared to Class II cavities with RMGIC liners. These results are in accordance to the study done by Mario Fernando De Goes et al (2008) ${ }^{12}$ who has stated that the hydrophobic low viscosity resin layer improves the polymerization of the adhesive resin mixture by inhibiting the uncured resin layer formed over the top of adhesive layer after the light irradiation, thus increasing the bond strength.

This study also revealed that the placement of a flowable liner under the composite restoration do not significantly increase the bond strengths that correlates to the results obtained by Andre Figueiredo Reis, Marcelo Giannini, Glaucia 
Maria Bovi Ambrosano, Daniel CN Chan, Roberto R Braga, Thomas J Hilton and Jack L Ferracane in 2003.13,14 These low bond strength values might be due to less availability of solid dentin for hybrid layer formation at the site of bonding.

The microtensile bond strengths of the composite resins lined with resin modified glass ionomer liners were inferior to the Flowable Liner Group could be due to low modulus of elasticity of RMGIC liners compared to the elastic modulus of the flowable composites, which cannot take the initial stress induced by polymerization shrinkage of the Z-250 composite resin leading to high force transmission of the shrinkage stress from the Z-250 composite resin in RMGIC Liner Group. Moreover, the higher $\mathrm{pH}$ and high viscosity of the Adper Single Bond 2 might have also contributed to the lesser micromechanical retention of the RMGIC liner leading to lesser wettability of the bonding agent on to surface, lowering the bond strengths of RMGIC to composite.

But WH Tate, KH Friedl, JM Powers ${ }^{15}$ in 1996 had got contradictory results to the present study and their results were in favour of RMGIC liners when compared to flowable composites and stated that the bonded interface of low modulus composite may stretch within the composite creating excessive strain within the bond. Later studies by Feilzer AJ, Davidson CL, De Gee AJ, Dauviller in 2000 also concluded that the glass ionomer liners reduce the contraction stresses more when compared to the resin composite liners.

In a similar vein the contradictory results to the current study are obtained by Labella R, Lambrechets P, Van Meerbeck B and Vanherle G in 1999, in which the authors have stated that the flowable composites have higher shrinkage values when compared to the hybrid composites and thus a potential for higher stresses at the bonded interface.

Recently, microtensile bond strengths of different adhesive systems was studied by Rashmirekha Mallick et al in 2015 and they concluded that interface bonded with the two adhesive systems had lower microtensile bond strength than those of dentin and resin composite. This shows that adhesive interface continues to be the weakest point in bonded aesthetic resin composite restoration. ${ }^{16}$

A study done by Cigdem Celik et al in 2013 revealed that microtensile bond strengths of composite repair can be enhanced by surface treatment with air abrasion. The adhesives used can be etch and rinse and two-step self-etch adhesives. ${ }^{17}$

Effect of different mechanical and chemical surface treatment on repaired bond strength of an indirect composite resin was evaluated by Soodabeh Kimyai et al in 2015. This study concluded that the surface preparation of the indirect composite resin with air abrasion and $\mathrm{Nd}$ : YAG laser resulted in a significant increase in the repair bond strength with air abrasion being more effective. The findings are in accordance with the study done by Cigdem Celik et al. ${ }^{18}$

The study done by Mehmet Cebe et al 2014 assessed the microtensile bond strength values to dentin with different one-step self-etching adhesive systems. Four different onestep self-etching adhesive systems including Clearfil S Bond Plus, Clearfil S Bond, Xeno V Bond and Adper Easy Bond were used. Clearfil S Bond Plus exhibited higher values. The most filled bonding resulted in providing higher bond strength to dentine. The results of the present study were consistent with the earlier studies. ${ }^{19}$

Microtensile bond strengths values of composite restorations with or without flowable liner were not statistically significant. Reason for not getting increased bond strength for Flowable Resin Liner Group might be due to the low filler content of the flowable liner that must have increased the shrinkage stresses.

SEM observations in the de-bonded specimens showed adhesive and cohesive failures at the interface of the dentin and the liner. Almost all the failures are adhesive with fractures occurring at the resin and the dentin interface. Few specimens in the resin modified glass ionomer group showed cohesive failure within the liner. SEM image of the glass ionomer liner showed that the bond strength of the liner to the dentin substrate is more stable than the chemical bonding within the liner, indicating that the weakest link in the RMGIC Liner Group is within the liner.

\section{CONCLUSION}

Within the Limitations of this Laboratory Study it can be Concluded that-

1. Both the flowable liner and the resin modified glass ionomer liner demonstrated good bond strengths to the dentin. Though the bond strength of the resin modified glass ionomer liner is less than the Flowable Liner Group, the bond strengths of the resin modified liner fulfil the required bond strengths of dentin, i.e. from 17 30 Mpa.

2. Flowable liner under the composite restoration demonstrated better bonding when compared to the resin modified glass ionomer liner.

3. SEM results of the debonded specimens predominantly showed adhesive type of failures at the dentin and the resin interface with the exception of few specimens in the resin modified group, which showed cohesive failure within the liner.

\section{ACKNOWLEDGEMENT}

The author would like to thank Dr. M. Jyothi, Dr. Roopesh and Dr. Mohan for kind support and timely suggestions during the period of this study. The author would like to thank the principal of Gitam Dental College and Hospital for unconditional help in conducting this study.

\section{REFERENCES}

[1] Meerbeek VB, De Munck J, Yoshida Y, et al. Buonocore memorial lecture. Adhesion to enamel and dentin: current status and future challenges. Oper Dent 2003;28(3):215-35.

[2] Spencer P, Ye Q, Park J, et al. Adhesive/dentin interface: the weak link in the composite restoration. Ann Biomed Eng 2010;38(6):1989-2003.

[3] Summit JB, Robbins JW, Hilton TJ, et al. Bonding to enamel and dentin. Fundamentals of operative dentistry. 3rd edn. Quintessennce publishing Co. Inc 2006:183-260.

[4] Bayne SC, Thompson JY, Swift EJ, et al. A characterization of first-generation flowable composites. J Am Dent Assoc 1998;129(5):567-77. 
[5] Unterbrink GL, Liebenberg WH. Flowable resin composites as filled adhesives: literature review and clinical recommendations. Quintessence Int 1999;30(4):249-57.

[6] Labella R, Lambrechts P, Meerbeck VB, et al. Polymerization shrinkage and elasticity of flowable composites and filled adhesives. Dent Mater 1999;15(2):128-37.

[7] Malmstrom HS, Schlueter M, Roach T, et al. Effect of thickness of flowable resins on marginal leakage in class II composite restorations. Oper Dent 2002;27(4):373-80.

[8] Kemp-Scholte CM, Davidson CL. Complete marginal seal of class $\mathrm{V}$ resin composite restorations affected by increased flexibility. J Dent Res 1990;69(6):1240-3.

[9] Feiltzer AJ, Davidson CL, De Gee AJ, et al. Visco-elastic parameters of dental restorative materials during setting. J Dent Res 2000;79(3):818-23.

[10] Hagge MS, Lindemuth JS, Mason JF, et al. Effect of four intermediate layer treatments on microleakage of class II composite restorations. Gen Dent 2001;49(5):489-95.

[11] Anderson-Wenckert IE, Dijken JWV, Horstedt P. Modified class II open sandwich restorations: evaluation of interfacial adaptation and influence of different restorative techniques. Eur J Oral Sci 2002;110(3):270-5.

[12] De Goes MF, Giannini M, Di Hipolito V, et al. Microtensile bond strength of adhesive systems to dentin with or without application of an intermediate flowable resin layer. Braz dent J 2008;19(1):51-6.
[13] Braga RR, Hilton TJ, Ferracane JL. Contraction stress of flowable composite materials and their efficacy as stress-relieving layers. Am Dent Assoc 2003;134(6): 721-8.

[14] Reis FA, Giannini M, Ambrosano GM, et al. The effects of filling techniques and a low-viscosity composite liner on bond strength to class II cavities. J Dent 2003;31(1):59-66.

[15] Tate WH, Friedl KH, Powers JM. Bond strength of composites to hybrid ionomers. Oper Dent 1996;21(4):147-52.

[16] Mallick R, Sarangi P, Mohanty S, et al. Micro-tensile bond strength of different adhesive systems on sound dentin and resin-based composite: an in-vitro study. J conservative dent 2015;18(5):379-83.

[17] Celik C, Cehreli BS, Bagis B, et al. Microtensile bond strength of composite-to composite repair with different surface treatments and adhesive systems. Journal of adhesive science and technology 2014;28(13):1264-76.

[18] Kimyai S, Oskoee SS, Mohammadi N, et al. Effect of different mechanical and chemical surface treatments on the repaired bond strength of an indirect composite resin. Lasers in medical science 2015;30(2):653-9.

[19] Cebe M, Adiguzel M, Cebe F, et al. Comparative evaluation of micro-tensile bond strength of one-step self-etching adhesive systems. Journal of restorative dentistry 2014;2(3):130-5. 